\title{
Corrigendum
}

\section{Corrigendum to “A Fuzzy Clustering Logic Life Loss Risk Evaluation Model for Dam-Break Floods"}

\author{
Yantao Zhu $\mathbb{D}^{1,2,3}$ Xinqiang Niu, ${ }^{4,5}$ Chongshi Gu $\mathbb{D}^{1,},{ }^{1,2,3}$ Bo Dai $\mathbb{D}^{1,2,3}$ and Lixian Huang ${ }^{6}$ \\ ${ }^{1}$ State Key Laboratory of Hydrology-Water Resources and Hydraulic Engineering, Hohai University, Nanjing, China \\ ${ }^{2}$ National Engineering Research Center of Water Resources Efficient Utilization and Engineering Safety, Hohai University, \\ Nanjing, China \\ ${ }^{3}$ College of Water Conservancy and Hydropower Engineering, Hohai University, Nanjing, China \\ ${ }^{4}$ Changjiang Institute of Survey, Planning, Design and Research, Wuhan, China \\ ${ }^{5}$ National Dam Safety Research Center, Wuhan, China \\ ${ }^{6}$ Materials Science and Engineering, University of California-Los Angeles, Los Angeles, CA, USA
}

Correspondence should be addressed to Chongshi Gu; csgu@hhu.edu.cn and Bo Dai; bo.dai@hhu.edu.cn

Received 20 November 2021; Accepted 20 November 2021; Published 4 February 2022

Copyright (c) 2022 Yantao Zhu et al. This is an open access article distributed under the Creative Commons Attribution License, which permits unrestricted use, distribution, and reproduction in any medium, provided the original work is properly cited.

In the article titled "A Fuzzy Clustering Logic Life Loss Risk Evaluation Model for Dam-Break Floods" [1], Figure 4 has been removed at the request of the authors to avoid potential conflicts in relation to the map data. The removal of Figure 4 does not impact the results or conclusions of the study.

\section{References}

[1] Y. Zhu, X. Niu, C. Gu, B. Dai, and L. Huang, "A fuzzy clustering logic life loss risk evaluation model for dam-break floods," Complexity, vol. 2021, Article ID 7093256, 15 pages, 2021. 